\title{
Observations from a Delphi Survey of administrators of U.S. nursing homes on oral neglect guidelines: a brief report
}

\author{
Ralph V Katz ( $\sim$ ralph.katz@nyu.edu ) \\ Sharon M Casey \\ New York University College of Dentistry \\ Barbara J Smith \\ New York University College of Dentistry \\ Shulamite Huang \\ New York University College of Dentistry
}

\section{Research note}

Keywords: Brief Report, Commentary, Oral Neglect, Nursing Homes, Vulnerable Elderly, Nursing Home Administrators, Delphi Survey

Posted Date: April 8th, 2020

DOI: https://doi.org/10.21203/rs.3.rs-20489/v1

License: (c) (i) This work is licensed under a Creative Commons Attribution 4.0 International License. Read Full License 


\section{Abstract}

Objective: The goal of this Delphi survey was to obtain the opinion of the chief/head administrators of nationally recognized award-winning Long-Term Care (LTC) nursing homes in the U.S. regarding previously established Oral Neglect in Institutionalized Elderly (ONilE) timelines.

Results: Only two of the 56 invited expert panelists completed Round 1 of this ONilE Delphi survey, despite the use of several methodologic approaches to facilitate their participation. Despite their impeccable credentials as dedicated, highly accomplished administrators of LTC nursing facilities across the U.S., this pool of potential chief/head LTC administrators panelists (unlike previously surveyed national expert panels of other key stakeholders, such as academic geriatric dentists, physician and nurses) abrogated their professional responsibility to the vulnerable elderly under their care by, essentially, refusing to participate in this survey, i.e., by refusing to 'voice their opinion' as one key stakeholder in this much needed discussion.

\section{Introduction}

Elder abuse continues to be a serious public health concern in healthcare settings, especially in the U.S. (Truong, Burnes, Alaggia, Elman, \& Rosen, 2019). Editorials in The American Journal of Public Health and The Lancet have specifically addressed the fact that oral health has been long neglected globally stating that the elderly "suffer disproportionately from oral diseases, and the problem is particularly acute for individuals in LTC facilities, (Lamster, 2004) and "that radical public health actions are needed" including a clear need for "broader accessibility". (The Lancet Editorial Board, 2019) These two broad and urgent calls for the need to address accessibility to oral health care has joined recent calls by the World Health Organization, the Federation Dentaire International, and the International Association for Dental Research for vastly improving accessibility to oral health care for the elderly. (Miyazaki, Jones, \& Beltran-Aguila, 2017; Ghezzi, Koybayashi, Park, \& Sirsilapanan, 2017; Slack-Smith, Hearn, Wilson, \& Wright, 2015)

The specific need to monitor oral health in elderly individuals is a "matter not only of public health, but also of human rights" (Fukai, Ogawa, \& Hescot, 2017; Hyde, Dupuis, Mariri, \& Dartevelle, 2017) as it is well recognized now that "oral health is closely related to systemic health" (Dorfer, Benz, Aida, \& Campard, 2017) as well as overall quality of life for this expanding demographic. (Shimazaki, Soh, Koga, \& Miyazaki, 2004; Zenthofer, Rammelsberg, Cabrera, Schroder, \& Hassel, 2014) In fact, the Justice in Aging Organization has praised the fact that the upcoming 2020 U.S. Surgeon General's Report will "focus on vulnerable populations, including older adults". (U.S. Surgeon-General Comments, JusticeinAging.pdf, 2019) given that published research on who constitutes the vulnerable in matters of health has specifically identified 'the elderly' as the leading vulnerable group in the U.S. (Chiu \& Katz, 2011)

These recent calls for developing global systems to ensure appropriate access to oral health care for the elderly in a globally ageing population, come nearly a decade after the initial publication of 2010 (ONiIE) Delphi Survey. The first Delphi ONilE Project, using a panel of geriatric academic experts developed minimal U.S. national standards that could be used to avoid oral neglect for the elderly residents of LTC nursing homes (Katz, Smith, Berkey, Guset, \& O'Connor, 2010) a minimum standard definition that was subsequently approved and endorsed for use in the U.S. by both the American Society for Geriatric Dentistry and the Special Care in Dentistry Association. (Casey, Katz, Huang, \& Smith, 2019) A second ONilE Delphi Survey, using a panel of leading U.S. 
academic geriatric physicians and nurses, agreed with the timelines for defining oral neglect as set in that first ONilE survey (Casey, Katz, Huang, \& Smith, 2019).

The use of a Delphi Survey to obtain expert opinion has been long-established as a valid research approach (Dalkey and Helmer, 1963; Helmer, 1967) and has recently been re-evaluated and praised as a valid and much needed research approach in today's Evidence-Based Medicine era. (Hohmann, Brand, Rossi and Lubowitz, 2018)

The goal of this Delphi Survey, the third in the ONilE Project, was designed to obtain the opinion of the chief/head administrators of U.S. LTC nursing homes regarding the guidelines previously established for avoiding oral neglect by nationally recognized expert panels of geriatric health care providers, i.e., national academic leaders who were dentists, physicians and nurses.

\section{Methods}

To ensure that this third ONiIE Delphi survey would have a comparable national leadership composition to the prior expert ONilE panelists from dentistry, medicine and nursing used in the first two ONilE Delphi surveys, a selection process was used to ensure that only the chief/head administrators of nationally-recognized award winning LTC nursing homes in the U.S. were invited to serve on the expert panel. Specifically, the pool of invited panelists for this third ONilE survey only included the 56 chief/head administrators of the American Health Care Association/National Center for Assisted Living (AHCA/NCAL) National Quality Award Program whose LTC facility had been recognized as winners of the AHCA/NCAL Gold (Excellence in Quality) and Silver (Achievement in Quality) Awards in 2018. (https:www.ahcanal.org/quality_improvement/quality_award? Pages/QualityAwardRecipients.aspx, 2018) Prior research has established that the LTC facilities that receive the Gold or Silver AHCA/NACL Awards provide a higher, sustained quality of care for their residents over a period of time as compared not only to all other U.S. LTC nursing homes. (Castle, Olson, Shah, \& Hansen, 2018)

The same invitation email as previously used in prior ONilE Delphi Surveys was sent to all 56 chief/head administrators whose U.S. LTC nursing facilities had been awarded a Gold ( $n=4)$ or Silver (52) AHCL/NACL Award in 2018 for whom specific email addresses could be identified. The email informed the recipient of the purpose and participatory details of the survey and asked to recipient to complete the online REDCap survey form (see Table 1). The email also explained that it would take only five minutes of their time, to indicate whether-or notthey agreed with timelines established for oral neglect occurrence in the previous two Delphi surveys by geriatric academic leaders in dentistry, medicine and nursing.

As is typical within the Delphi survey technique, invited panelists were informed that their names and professional affiliation-as participatory panelists-would be published in the final article allowing the readership to see, and to judge, the quality of the expert panel. They were further assured that the data from the findings would only be published 'in the aggregate', i.e., no individual response to any item could be identified with any one panelist. This typical Delphi Survey technique guarantee of simultaneous recognition as a survey panel participant with full anonymity provided regarding any panelist's specific data responses was offered to the invited panelists in this ONilE \#4 survey for two rounds of sent invitations.

Given the very limited response rate after two rounds of invitations, a third email invitation was sent to the nonresponding expert panelists of these selected 'best LTC nursing facilities' in the U.S. This third invitation provided 
each invited panelists the opportunity (via a check-off box) to not have their name published as a member of the panel, i.e., offered them complete anonymity in any published article meaning anonymity for their 'name being listed' as well as for their 'response data'. Despite these subsequent attempts, including this modified invitation guaranteeing complete anonymity to obtain a fuller response rate from these chief/head administrators of LTC nursing facilities, no other chief/head administrative panelists ever responded with a completed survey form.

This Delphi survey of U.S. nationally-recognized experts was reviewed by the IRB of New York University and categorized as Not Human Research (NHR) under the revised Common Rule Guidelines from NIH.

\section{Results}

Of the 56 invited expert panelists, only two ever completed the ONilE \#4 survey representing a 3.6\% response rate. These two completed surveys were received in response to Round 1, within 4 days of the initial invitation as sent to all 56 of the experts. Both of these responding expert panelists indicated that they did agree with the timeline for oral neglect as previously established by the dental, medical and nursing expert panels, i.e., $>7$ days for acute conditions and $>34$ days for chronic conditions.

\section{Discussion}

Despite following the time-proven approach to identifying an expert panel for a Delphi survey which has consistently proven successful in our seven conducted Delphi research projects over the past five decades (Katz and Frey, 1976; Slaughter, Katz, \& Grasso, 1999; Katz et al, 2010; Das, Jahangiri, \& Katz, 2012; Li, Morse, \& Katz, 2013; Katz, Tillman, Bloch, Stojanovic, \& Kaira, 2015; Casey et al, 2019), this is the first time we have 'literally failed' to engage and obtain an expert panel for a Delphi survey. On the one hand, that obviously prevents us discussing and interpreting the findings to our planned and posed Delphi survey questions for this set of chief/head administrators of U.S. award-winning LTC nursing homes. One the other hand, the fact that this set of chief/head administrators of U.S. award-winning LTC nursing homes would not engage in an exploration to set a minimum standard for oral neglect on behalf of the residents of their LTC nursing homes is-in itself-a very telling finding. The fact that they uniformly-and individually-chose to 'neglect' the topic of oral neglect is a very unfortunate 'oral neglect' of this vital topic by this very key stakeholder group.

Unfortunately, this is not the first time that executive directors of U.S. LTC nursing home facilities-a key set of stakeholders in this issue-have, basically, refused to participate in a survey to explore and define the issues of oral neglect and oral care in the residents of their care facilities. In 2005, researchers attempted to conduct a survey on this topic in the state of Ohio and sent out 1,018 surveys to all the executive directors of nursing homes in that state. (Pyle, Jasinevicius, Sawyer, \& Madsen, 2005) Given a dismal 33\% response rate, the researchers stated that they could conclude very little on the topic. Noting that $53 \%$ of those who did respond rated the oral health of their LTC residents as fair or poor, the researchers did conclude that these executive directors clearly placed a very low priority on oral health.

The sad reality is that virtually every published descriptive epidemiologic oral health survey of institutionalized elders seems to uniformly report an absence of good oral health in the residents, usually accompanied by noting the absence of proper oral health care availability and accessibility. (Ettinger, O'Toole, Warren, Levy, \& Hand, 2000; Dye, Fisher, Yellowitz, Fryar, \& Vargas, 2007; Guay, 2005; Smith \& Shay, 2005; Smith, Ghezzi, Manz, \& Markova, 2008; Thai, Shuman, \& Davidson, 1997; Sfikas, 1999; Helgeson, Smith, Johnsen, \& Ebert, 
2002) And, this has persisted as the repeatedly drawn epidemiologic picture of oral health in the institutionalized elderly over the past 50 years.

Despite these impeccable credentials as dedicated, highly accomplished administrators of LTC nursing facilities across the U.S., $96.3 \%$ of this pool of potential panelists abrogated their professional responsibility to the vulnerable elderly under their care by, essentially, refusing to participate in this survey. Rather than add their profession's opinion and voice-as a critical stakeholder and concerned geriatric professional-to the chorus of geriatric health professionals (dentists, physicians and nurses) who previously had already participated in developing a definition and time line for defining the condition of oral neglect for institutionalized elderly living in LTC nursing facilities.

While one could appreciate that of the all the Delphi surveyed professional groups who have been invited in our published series of Delphi studies to voice their expert opinion on developing a definition of oral neglect for the vulnerable elderly residents of LTC nursing facilities, LTC administrators would likely 'directly feel the pinch' of

a definition of oral neglect more than the previously participating sets of geriatric health care experts (i.e., dentists, physicians, and nurses). Nevertheless, it is shocking that only 2 Award-winning LTC administrators (i.e., a mere $3.6 \%$ ) felt the professional obligation to 'get into the discussion' and 'to bring their viewpoint' to this evolving definition of oral neglect for the vulnerable elderly living in LTC nursing facilities across the U.S

\section{Conclusion}

The fact that $96.3 \%$ of the 56 administrators of award-winning LTC residential facilities in the U.S, who are major shareholders in the daily care of LTC nursing facility residents, refused to participate in a brief online survey to address this critical issue of defining a minimum standard of oral neglect so central to the well-being and health of those vulnerable elderly under their care turns the topic of this survey, i.e., oral neglect, into an unintended double entendre. Despite our research team's acute pre-survey awareness of the pressures that each of these LTC administrators would feel in 'helping to define' oral neglect in their residents which led us to select 'the very best of the best U.S. nursing homes' for our expert panel pool (i.e., only the Gold and Silver AHCA/NCAL Award winners), they sadly chose 'no voice' over 'expressing their voice' despite their critical professional duty to house, care for, and protect these vulnerable elderly.

\section{Limitations}

- Extremely low participation rate despite properly designed and conducted Delphi

Survey technique which even adjusted recruitment incentives to work to enhance participation.

- Refusal of these U.S. award administrators of Long-Term Care Nursing Homes to participate, as key and critical gatekeepers, in this dialogue on defining oral neglect in their institutionalized elderly residents.

\section{Abbreviations}


AHCA/NCAL: American Health Care Association/National Center for Assisted Living

National Quality Award

LTC: Long-Term Care

ONilE: Oral Neglect in Institutionalized Elderly

\section{Declarations}

\section{Ethics approval and consent to participate:}

This Delphi survey of U.S. nationally-recognized experts was reviewed by the IRB of New York University and categorized as Not Human Research (NHR) under the revised Common Rule Guidelines from NIH.

Consent for publication: Not Applicable

\section{Availability of data and materials:}

The ONilE Delphi Survey Questionnaire is fully shown in Table 1....and there is NO DATA to share.

\section{Competing interest:}

The authors declare that they have no competing interests to report.

\section{Funding:}

No funds were obtained to support this study.

\section{Authors' contributions:}

Ralph V. Katz: conceived the project, wrote the first draft of the manuscript, edited the later versions of the manuscript; contributed the analysis of non-participation by the invited panelists, and serves as the Corresponding Author.

Sharon M. Casey: developed and administered the RedCap online Delphi Survey, contributed the analysis of nonparticipation by the invited panelist, and edited the later versions of the manuscript. 
Barbara J Smith: edited the later versions of the manuscript and contributed the analysis of non-participation by the invited panelists.

Shulamite Huang: edited the later versions of the manuscript and contributed the analysis of non-participation by the invited panelists

Acknowledgements: Not applicable.

\section{References}

Casey SM, Katz RV, Hu ang S, Smith BJ. Geriatric health experts validate oral neglect timelines in institutionalized elderly. Journal of Applied Gerontology 2019 published in Online First 11 Oct 2019:

DOI:10.1177/0733464819880085.

Castle N, Olson D, Shah U, Hansen K. Do Recipients of an Association-Sponsored Program Experience Better Quality Outcomes Compared With Other Nursing Facilities Across the United States? Journal of Applied Gerontology 2018 37(11)1368-1390.

Chiu C, Katz RV. Identifying the 'Vulnerables' in Biomedical Research: the vox populis from the Tuskegee Legacy Project. J Public Health Dent 2011 71:220-228.

Dalkey NC, Helmer O. Experimental applications of the Delphi Method: the use of experts. Management Sci 9:458467, 1963.

Das, KP, Jahangiri L, Katz RV, First Choice Standard of Care for the Edentulous Mandible: A Delphi Survey of U.S. Academic Prosthodontists. JADA 2012 143(8)881-889.

Dorfer C, Benz C, Aida J, Campard G. The relationship of oral health with general health and NCDs: a brief review. International Dental Journal 2017 67(Issue S2):14-18. 
Dye BA, Fisher MA, Yellowitz JA, Fryar CD, Vargas CM. Receipt of dental care, dental status and workforce in U.S. nursing homes: 1997. National Nursing Home Survey. Spec Care Dentist 2007;27(5):177-186.

Ettinger RL, O'Toole C, Warren J, Levy S, Hand JS. Nursing directors' perceptions of the dental components of the Minimum Data Set (MDS) in nursing homes. Spec Care Dentist 2000;20(1):23-27.

Fukai K, Ogawa H, Hescot, P. International Dental Journal 2017 67(Issue S2):3-6.

Ghezzi EM, Koybayashi K, Park D, Sirsilapanan P. International Dental Journal 2017 67(Issue S2):26-33.

Guay $\mathrm{AH}$. The oral health status of nursing home residents: what do we need to know? J Dent Educ 2005;69(9):1015-1017.

Helgeson MJ, Smith BJ, Johnsen M, Ebert C. Dental considerations for the frail elderly. Spec Care Dentist 2002;22(3 suppl):40S-55S.

Helmer O. Analysis of Future: Delphi Method. Rand Corporation. 1967, pg 3558.

Hohmann E, Brand J, Rossi M, Lubowitz J. Expert Opinion is Necessary: Delphi Panel Methodology Facilitates a Scientific Approach to Consensus. Arthroscopy. 2018 34(2) 349-351.

https://www.ahcancal.org/quality_improvement/quality_award/Pages/QualityAwardRecipients.aspx. Last accessed on July 1, 2018

Hyde S, Dupuis V, Mariri BP, Dartevelle S. Prevention of tooth loss and dental pain for reducing the global burden of oral diseases. International Dental Journal 2017 67(Issue S2):19-25.

Katz RV, Smith BJ, Berkey DB, Guset A, O’Connor MP. Defining Oral Neglect in Instititionalized Elderly: a Consensus Definition for the Protection of Vulnerable Elderly People. JADA 2010 141:433-440. 
Katz RV, and Frey BJ. Oral Health Services: A Delphi Technique Estimation of Their Role in Adult In-Patient Rehabilitation Programs. Arch Phys Med and Rehab. 57:183-88, April, 1976.

Katz RV, Tillman HH, Bloch RM, Stojanovic M, Kaira A. Revisiting the Status of Oral Health Services in Adult PM\&R Programs: a 40-year follow-up survey. Spec Care Dent 2015 35(5):214-220.

Lamster IB, Editorial 'Oral health care services for older adults: a looming crisis'. Am J Public Health 2004 94(5):699-702.

Li L, Morse DE, Katz RV. What Constitutes a Proper Routine Oral Cancer Examination by a General Dentist?: a national consensus opinion of U.S. experts. Oral Medicine, Oral Pathology, Oral Surgery and Oral Radiology 2013 Nov11 6(5):e379-e386.

Miyazaki H, Jones JA, Beltran-Aguila ED. International Dental Journal 2017 67(Issue S2):3-41.

Pyle MA, Jasinevicius TR, Sawyer DR, Madsen J. Nursing home executive directors' perception of oral care in long-term care facilities. Spec Care Dentist 2005 25(2)111-117.

Slack-Smith LM, Hearn L, Wilson DF, Wright FAC. Geriatric dentistry, teaching and future directions. Australian Dental Journal 2015 60(1 Suppl):125-130.

Shimazaki Y, Soh I, Koga T. Miyazaki H. Relationship between dental care and oral health in institutionalized elderly people in Japan. Journal of Oral Rehabilitation 2004 31(9):837-842

Slaughter A, Katz RV and Grasso JE, Perceptions of denture adhesives: a Delphi Technique Survey of Academic Prosthodontists J Pros Dent 1999 82(1):80-89.

Sfikas PM. Reporting abuse and neglect. JADA 1999;130(12):1797-1799. 
Smith BJ, Shay K. What predicts oral health stability in a long tercare population? Spec Care Dentist 2005;25(3):150-157.

Smith BJ, Ghezzi EM, Manz MC, Markova CP. Perceptions of oral health adequacy and access in Michigan nursing facilities. Gerodontology 2008;25(2):89-98.

Surgeon-General, https:www.justiceinaging.org/wp-content/uploads/2019/01/Surgeon-GeneralComments_JusticeinAging.pdf. last accessed on 7/30/19.

The Lancet Editorial Board, Oral Health at a tipping point. The Lancet 2019 394:188.

Truong C, Burnes D, Alaggia R, Elman A \& Rosen T. Disclosure among victims of elder abuse in healthcare settings: a missing piece in the overall effort toward detection. Journal of Elder Abuse \& Neglect. 2019 31(2):181190.

Thai PH, Shuman SK, Davidson GB. Nurses' dental assessments and subsequent care in Minnesota nursing homes. Spec Care Dentist 1997;17(1):13-18.

Twin, A. https://www.investopedia.com/terms/d/delphi-method.asp. Delphi Method: reviewed by Alexandra Twin. Last accessed on April 13, 2019.

Zenthofer A, Rammelsberg P, Cabrera T, Schroder J. Hassel AJ. Determinants of oral health-related quality of life of the institutionalized elderly. Psychogeriatrics 2014 14(4):247-254.

\section{Table 1}

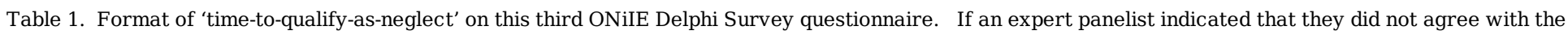

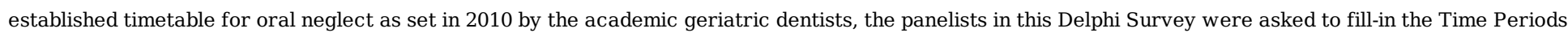

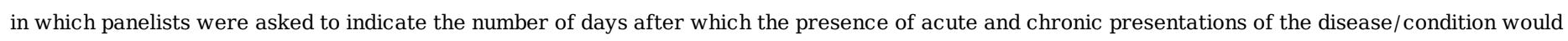
constitute neglect for the 'Detected-to-Dx' Phase and for the 'Dx-to-Care' Phase, where 'Dx' = Diagnosis.

$\begin{array}{cc}\begin{array}{cc}\text { TIME Period 1 } \\ \text { (or 'Detected-to-Dx' Phase) }\end{array} & \begin{array}{c}\text { TIME Period 2 } \\ \text { (or 'Dx-to-Care' Phase) }\end{array} \\ \begin{array}{c}\text { Indicate \# of days } \\ \text { after which failure to }\end{array} & \begin{array}{c}\text { Indicate \# of days } \\ \text { ave a follow-up Dental }\end{array} \\ \text { have failure to }\end{array}$

Page 10/11 

oral neglect.
ACUTE $^{1}$

fill-in
\# of days - TIME 1
fill-in
\# of days - TIME 2

CHRONIC $^{1} \quad$ fill-in \# of days - TIME 1

$\frac{\text { fill-in }}{\text { \# of days - TIME } 2}$

${ }^{1}$ Acute vs Chronic Oral Diseases/Conditions:

Acute oral disease/condition: any oral disease/condition with pain and/or potential for serious sequela if not attended to rapidly, e.g., facial swelling, abscess, or serious bleeding.

Chronic oral disease/condition: any other oral disease/condition

Time Period to Qualify as Oral Neglect:

$$
\text { ß-------Time Period } 1 \text {--------à }
$$

Time A

A ß----'Detected-to-Dx*’ Phase -à
ß-------Time Period 2---------à

Time $B$

Time $C$

Time $\mathbf{A}=$ The disease/condition first comes to the attention of the nursing home staff, dental hygienist or dentist.

Time $\mathbf{B}=\mathrm{A}$ follow-up diagnostic consult by the dentist is performed.

Time $\mathbf{C}=$ The point at which either:

1) the treatment is initiated for the diagnosed condition (this phase only goes to the initiation of treatment--it does not include the time to complete treatment), or

2) the patient (or guardian) refuses treatment for the diagnosed condition.

* Dx = diagnosed

** Care $=$ either provision of care or at least the offer of care 